Egyptian

Orthodontic Journal

\title{
EVALUATION OF PIEZOCISION IN RAPID CANINE RETRACTION
}

\author{
Ahmed R. Elkalza ${ }^{1}$
}

\section{ABSTRACT:}

Objective: The aim of this study is to evaluate the effectiveness of piezocision technique during rapid canine retraction. Materials and Methods: Material of the study consisted of ten patients of both genders, with age ranging from 16 to 25 years with malocclusion that require extraction of first premolars followed by canine retraction. Before starting canine retraction, maximum anchorage was ensured by placing mini-screws $10 \mathrm{~mm}$ in length and $1.6 \mathrm{~mm}$ in diameter between the second premolar and the first molar. In the experimental group, two vertical incisions were made on the buccal aspect mesial and distal to the canine. Piezo electric Knife was used to create cortical bone incisions to a depth of $3 \mathrm{~mm}$. Canine retraction was performed on 6oth sides using nicklel-titanium closed coil springs with force of $150 \mathrm{gm}$. Scanned casts were used to evaluate canine retraction movement on 6oth sides. Results: On comparing the two sides at the same time, it was found that there was a significant difference between both sides. It was found that the test side was significantly decreased more than the control side. Conclusion: Piezocisionfacilitated orthodontics is an effective treatment alternative that decreases the time required for canine retraction.

\section{INTRODUCTION}

During the last decade, many adult patients have been seeking orthodontic treatment. According to the American association of Orthodontics (AAO), the orthodontic treatment time can range from 12 to

1- Lecturer, Department of Orthodontics, Faculty of Dentistry, Alexandria University. 
36 months. Prolonged treatment time can lead to increased risk of several problems such as caries, periodontal disease and root resorption, and that is why many adult patients refuse orthodontic treatment. ${ }^{(1)}$

One of the primary goals of any orthodontist is to reduce orthodontic treatment time and increase patient satisfaction. Many methods have been assumed to decrease time of tooth movement by local or systemic administration of medicines such as prostaglandins, ${ }^{(2-6)}$ interleukins,${ }^{(7)}$ leukotriens, ${ }^{(8)}$ cyclic adenosine monophosphate ${ }^{(9)}$ and vitamin D. ${ }^{(10,11)}$ Mechanical or physical stimulation such as direct electrical current, ${ }^{(12)}$ pulsed electromagnetic field, ${ }^{(13)}$ and low-energy laser. ${ }^{(14)}$

Surgical methods have been attempted including dental distraction, alveolar corticotomies. ${ }^{(15,16)}$ According to the regional acceleratory phenomenon described by Frost and based on the work of Wilko et al, ${ }^{(17,18)}$ the bone tissue reacts with a rapid, transient, localized osteopenia and there is no loss of bone density. Clinically, the bone becomes more malleable and therefore, the teeth can be moved more quickly. ${ }^{(19)}$

Wilko's technique requires exposure of the underlying alveolar bone and creation of extensive decortications, but it is refused by many patients and orthodontists due to its invasive and traumatic nature. ${ }^{(20)}$

Dibart et al in 2009, ${ }^{(21)}$ introduced a new minimally invasive, periodontally accelerated orthodontic tooth movement procedure which is piezocision technique. This procedure combines micro incisions and local piezoelectric surgery to achieve similar results as decortication but with minimal trauma.

Vercellotti and Podesta ${ }^{(22)}$ used a piezoelectric knife instead of a high speed surgical bur to achieve rapid tooth movement with decreased trauma, due to safe and precise osteotomies without causing osteonecrotic damage. ${ }^{(23,24)}$ They also reported decreased orthodontic treatment time by 60 to $70 \%$ after the cuts are performed by the piezoelectric knife. Kim et al, ${ }^{(25)}$ introduced the cortision technique as a minimally invasive alternative to creat a surgical injury to the bone without flap reflection. 
Egyptian

Orthodontic Journal

Piezosicion technique combines microincisions to the buccal gingivae that allow the piezoelectric knife to decorticate the alveolar bone to initiate localized accelerating tooth movement. ${ }^{(26)}$

The piezosurgery device is basically an ultrasound machine with modulated frequency and a controlled tip vibration range. The ultrasonic frequency is modulated from 10, 30, and 60 cycles/s (Hz) to $29 \mathrm{KHz}$. The low frequency permits highly precise and safe hard tissue cutting. Nerves, vessels, and soft tissue are not injured by the micro-vibrations, which are optimally adjusted to target only miniralized tissue. The selective and thermally harmless nature of the piezosurgical instruments result in a low bleeding tendency. Power can be adjusted from 2.8 to $16 \mathrm{~W}$, with preset power settings for various types of bone density. The piezosurgery tip vibrates within a range of $60-200 \mathrm{~mm}$, which allows clean cutting with precise incisions. ${ }^{(27)}$ The tips of piezoelectric units work in a linear, back and forth motion, which is ideal for surgery.

\section{MATERIALS AND METHODS}

A split mouth sample consisted of 24 patients of both genders, with age ranging from 16 to 25 years, attended the orthodontic department clinic, Alexandria University. All patients had to fulfill the following criteria: malocclusion that requires extraction of maxillary first premolars, followed by canine retraction into the extraction site. Normal shape and structure of the maxillary canines, with no history of root canal treatment. Patients with good oral hygiene, and a healthy periodontal condition.

The patients were informed about the risks and benefits of the procedures performed and the consented to participate in this study. Ethical approval was obtained from the research ethical committee of the faculty of dentistry, Alexandria University.

The enrolled subjects were prepared for fixed orthodontic treatment by taking the routine orthodontic records (photographs, x-rays and dental casts). Afterwards, the patients were referred for extraction of both maxillary premolars. 
Egyptian

Orthodontic Journal

Orthodontic treatment was then started by banding and bonding of the maxillary arch using fixed orthodontic appliance (Damon Q self ligating system), and the stage of leveling and alignment was started. This stage was considered to be completed when a Co NiTi 0.016X0.025 arch wire was placed passively in the maxillary teeth.

Before starting canine retraction, maximum anchorage was ensured by placing mini-screws between the maxillary second premolars and the first molars on both sides. The mini-screw used was $10 \mathrm{~mm}$ in length and $1.6 \mathrm{~mm}$ in diameter. The mini-screws were placed under local anesthesia, and self-drilled into bone using a manual screw driver.

In the experimental group, the surgical procedure was performed with local infiltrative anesthesia to the mesial and distal sides of the canine. After local anesthesia, vertical interproximal incisions were made, $5 \mathrm{~mm}$ apical to the mesial and distal interdental papilla of the canine, on the buccal aspect using surgical blade No. 15. Incisions were extending $10 \mathrm{~mm}$ length apically, and going through the periosteum, allowing the blade to reach the alveolar bone. A Piezo surgical knife (Piezomed, tip B 1) was used to create the cortical bone incision through the gingival opening to a depth of $3 \mathrm{~mm}$ approximately. When the corticotomies were finished, the patients were discharged under antibiotic and analgesic cover. The patients reported no discomfort and pain and the surgical area was fully healed after 1 week from operation. There was no symptoms of inflammation and edema. After the operation, canine retraction was performed immediately on both sides using nickel-titanium closed-coil springs with a force of 150 grams applied on each side. (figure 2 through 5)

Alginate impressions were taken before, during, and after canine retraction, and the impressions were poured up with stone and dental casts were digitally scanned, and measurements were performed on the scanned casts to evaluate the anteroposterior canine movement. (figure 6) 


\section{RESULTS}

\section{Statistical analysis:}

The Data was collected and entered into the personal computer. Statistical analysis was done using Statistical Package for Social Sciences (SPSS/version 20) software.

Arthematic mean and standard deviation was calculated for numerical data and t-test was used to compare two groups while for more than two groups ANOVA test was used. The level of significant was 0.05.

Table (1): Comparison between the two sides regarding the distance.

\begin{tabular}{|l|c|c|c|c|}
\hline & Rt test side & Lt Control side & t-test & P \\
\hline $\begin{array}{l}\text { Start } \\
\text { Range }\end{array}$ & $9-18$ & $9-17$ & 1.23 & 0.365 \\
Mean \pm S.D. & $12.4 \pm 2.67$ & $12 \pm 2.45$ & & \\
\hline 1 month & & & 2.11 & $0.032^{*}$ \\
Range & $6-13$ & $8-15$ & & \\
Mean \pm S.D. & $8.8 \pm 1.99$ & $10.7 \pm 2.31$ & 3.21 & $0.014^{*}$ \\
\hline 2 months & $4-9$ & $6-12$ & & \\
Range & $6.8 \pm 1.75$ & $8.8 \pm 1.99$ & & \\
Mean \pm S.D. & $3-7$ & $5-10$ & & \\
\hline 3 months & $4.9 \pm 1.52$ & $6.9 \pm 1.79$ & & \\
Range & 16.51 & 11.23 & & \\
Mean \pm S.D. & $0.0001^{*}$ & $0.0021 *$ & & \\
\hline ANOVA & & & & \\
P2 & & & & \\
\hline
\end{tabular}

On comparing the two side at the same time, it was found that there was a significant difference between the two sides at 1,2 and 3 months. On comparing the change of distance in the same side, it was found that the test side was significantly decreased more than the control side. 


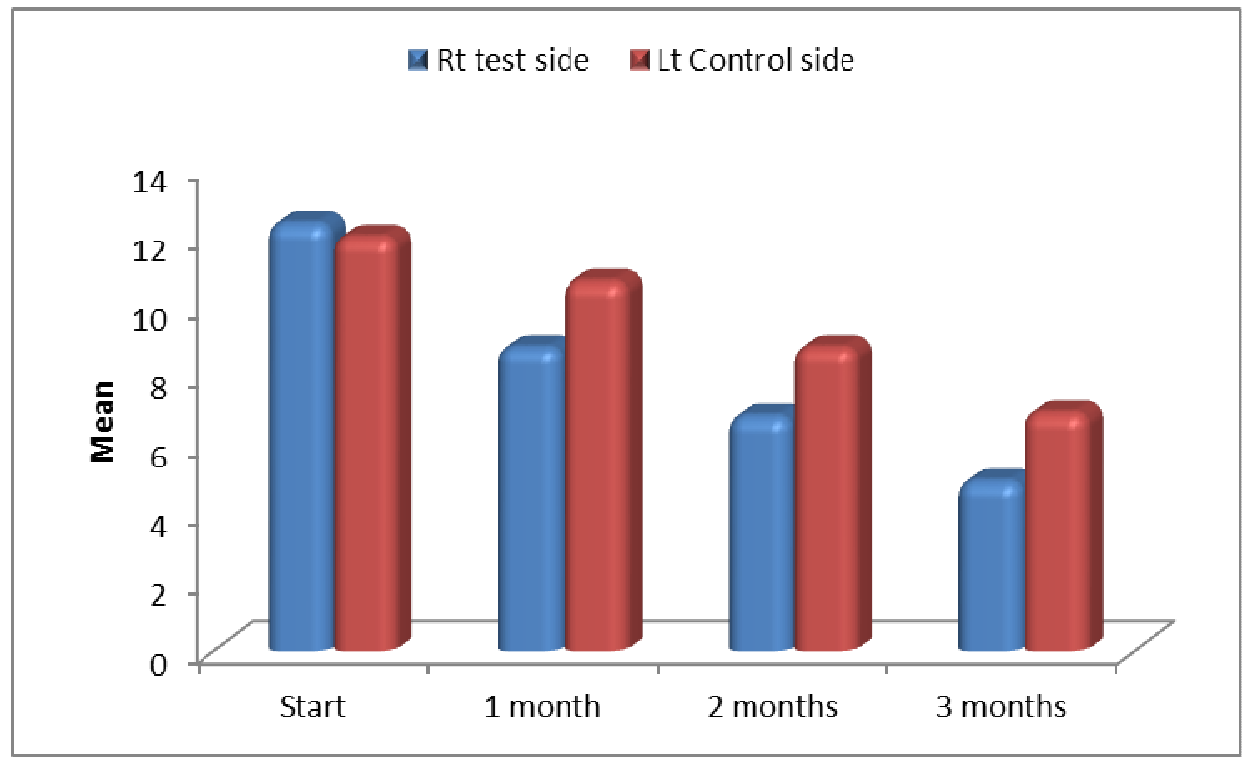

Fig.1: Comparison between the two sides regarding the distance.

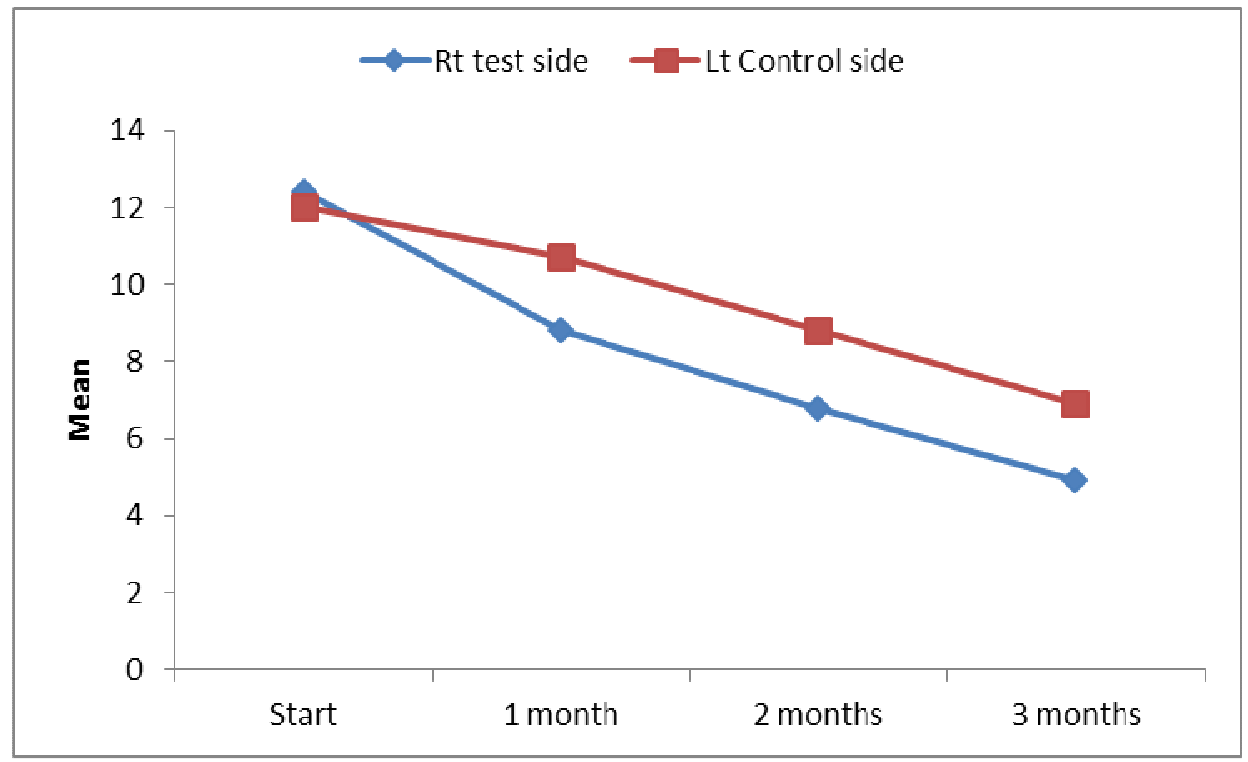

Volume 51 - June 2017 


\section{Egyptian \\ Orthodontic Journal}

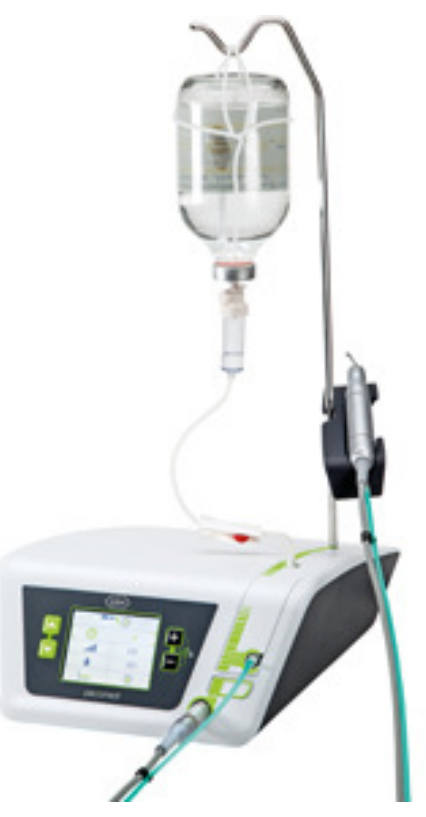

Fig.2 Piezomed device

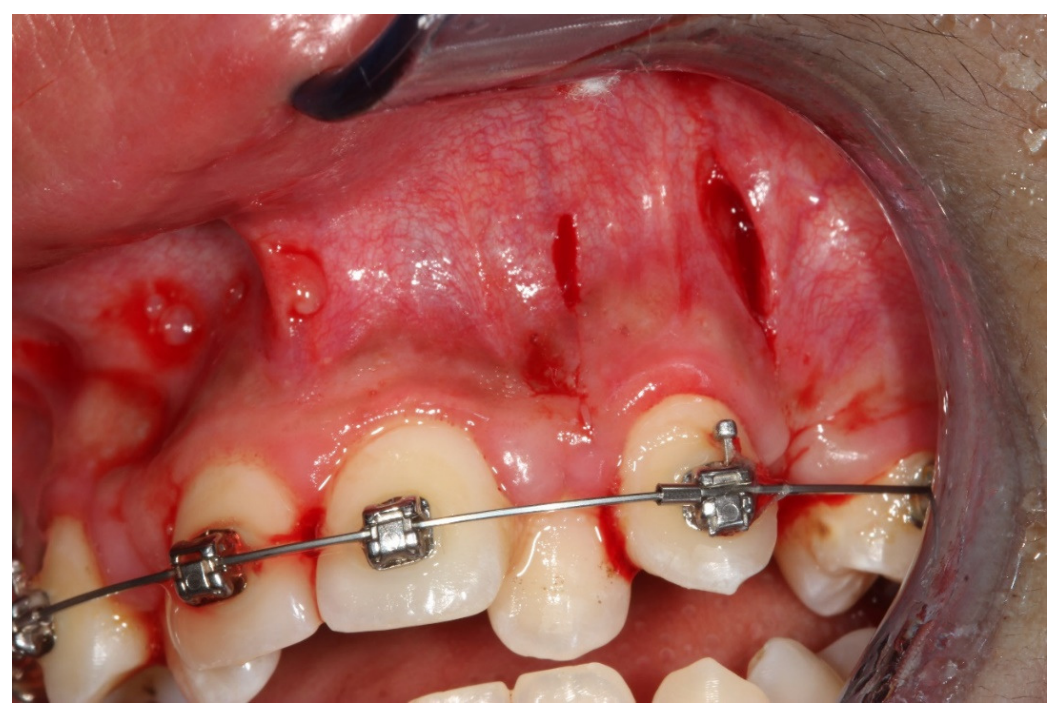

Fig.3 Interproximal vertical incisions using surgical blade No.15 


\section{Egyptian}

Orthodontic Journal

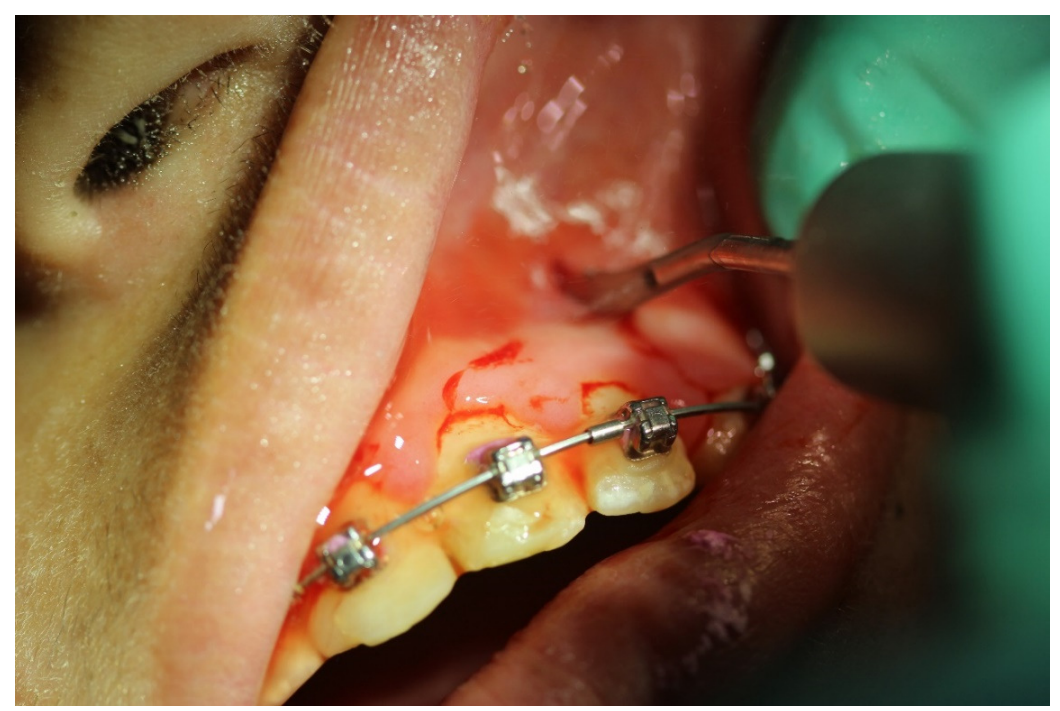

Fig.4 Piezo electric knife performing cortical bone incisions

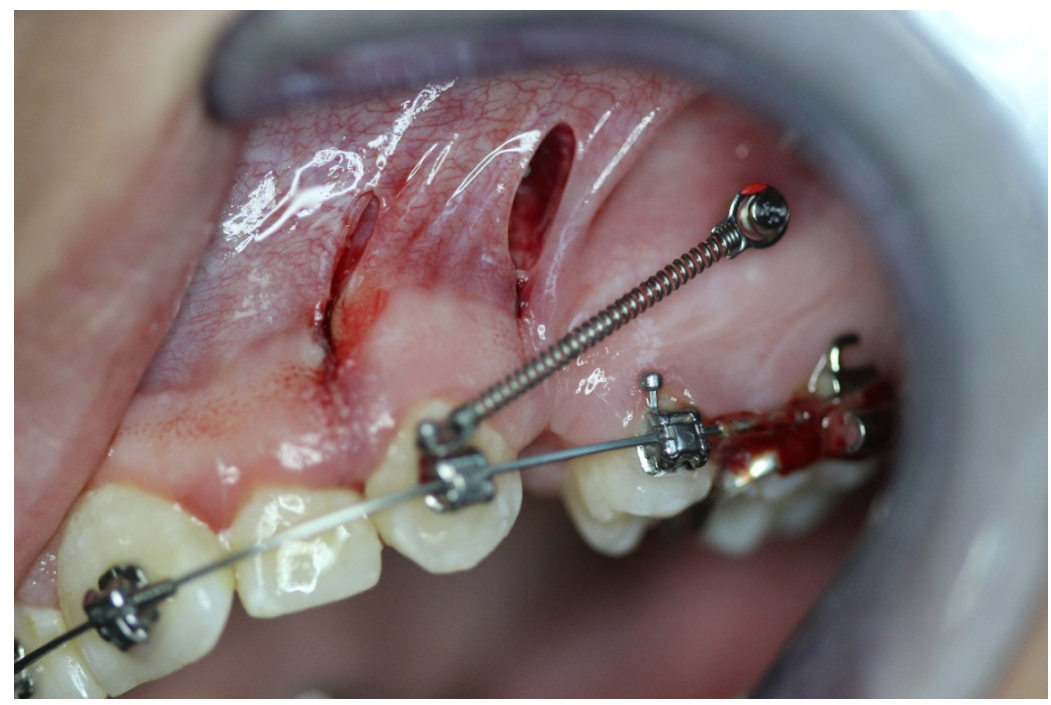

Fig.5 Canine retraction performed using nickel-titanium closed coil spring 


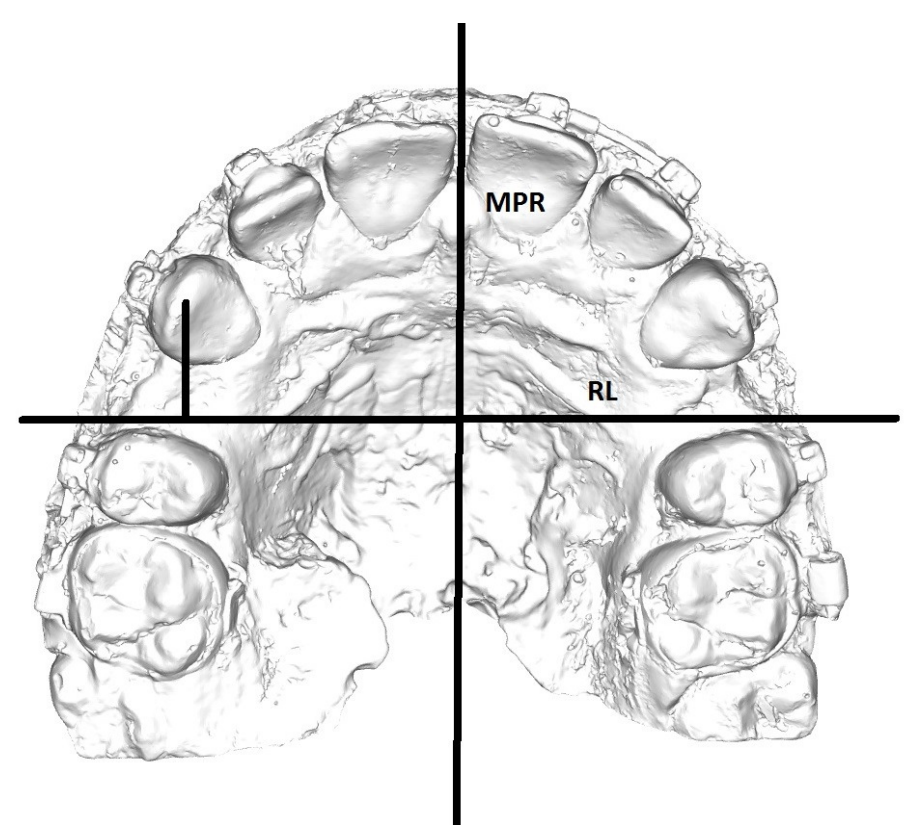

Fig.6 Digitally scanned cast with reference lines, the midpalatine raphe (MPR) and rugae line (RL) projecting from third right rugae

\section{DISCUSSION}

Piezocision has been studied to assess advantages and disadvantages of such a technique for decreasing treatment time for orthodontic patients. The rate of canine retraction movement was significantly greater in the experimental side than in the control side during the entire follow-up period. ${ }^{(28)}$

Different research studies focused on rapid orthodontic tooth movement recently, aiming for short overall treatment time, few complications and more patient satisfaction. Different approaches have been demonstrated to stimulate rate of orthodontic tooth movement such as prostaglandin local injection and osteocalcin injection, but these procedures are biomechanical in nature and are limited to animal model. On the other hand, surgical injury of the cortical bone adjacent to the area of aimed tooth movement also has been studied and showed rapid tooth movement due to biochemical initiation. ${ }^{(21,23,29,30,31)}$ 
Egyptian

Orthodontic Journal

Piezocision technique was first applied by Debart by placing buccal gingival incisions followed by buccal cortical incisions using piezo surgical knife. Hasan reported that piezocision is a promising tooth movement acceleration technique because of its beneficial effect on periodontium, aesthetics and orthodontics. ${ }^{(29,30,32,33,34)}$

The piezoelectric knife is safe and precise without causing any osteonecrosis. It works only on mineralized tissues, sparing soft tissue and its blood supply. Piezocision showed similar clinical outcome when compared to decortication, but has the advantage of being quick, minimally invasive and less traumatic to the patient. ${ }^{(29)}$

\section{CONCLUSION}

Piezocision facilitated orthodontics is an effective treatment alternative that decreases the time required for tooth movement with the advantage of being minimally invasive and less traumatic to the patient.

\section{REFERENCE}

1) Aylikco O, Sakin C. Piezocision-assisted canine distalization. J Orthod Res 2013;1:70-6.

2) Chumbley AB, Tuncay OC. The effect of indomethacin on the rate of tooth movement in cats. J Dent Res 1981; 60:596.

3) Chumbley AB, Tuncay OC. The effects of indomethacin (an asprin like drug) on rate of orthodontic tooth movement. Am J Orthod 1986;89:312-4.

4) Yamasaki K, Shibata Y, Fukuhara T. The effect of prostaglandins on experimental tooth movement in monkeys. J Dent Res 1982;61:1444-6.

5) Yamasaki K, Shibata Y, Imai S, Shibasaki Y, Fukuhara T. Clinical application of prostaglandin E1 (PGE1) upon orthodontic tooth movement. Am J Orthod 1984;85:508-18.

6) Lee W. Experimental study of the effect of prostaglandin administration on tooth movement with particular emphasis on the relationship to the method of PGE1 administration. Am J Orthod Dentofacial Orthop 1990;98:231-41. 
7) Hou Y, Liang T, Luo C. Effects of IL-1 on experimental tooth movement in rabbits. Chin J Stoma 1997;32:46-8.

8) Mohamed AH, Tataksi DN, Dziak R. Leukotriens in orthodontic tooth movement. Am J Orthod Dentofacial Orthop 1989;95:231-7.

9) Yamasaki $\mathrm{K}$. The role of cyclic AMP, calcium, and prostaglandins in the induction of osteoclastic bone resorption associated with experimental tooth movement. J Dent Res 1983;62:877-81.

10) Takano-Yamamoto T, Kawakami M, Yamashiro T. Effect of age on the rate of tooth movement in combination with local use of 1,25 OH) 2D3 and mechanical force in rat. J Dent Res 1992;71:1487-92.

11) Collins MK, Sinclair PM. The local use of vitamin D to increase the rate of orthodontic tooth movement. Amj J Orthod Dentofacial Orthop 1988;94:278-84.

12) Davidovitch Z, Finkelson MD, Steigmen S, Shanfeld JL, Montgomery PC, Lorostoff E. Electric currents, bone remodeling and orthodontic tooth movement and periodontal cyclic nucleotide levels by combined force and electric current. Am J Orthod 1980;77:33-47.

13) Stark TM, Sinclair PM. Effect of pulsed electromagnetic fields on orthodontic tooth movement. Am J Orthod Dentofacial Orthop 1987;91:91-104.

14) Derendeliler MA, Sinclair PM, Kusy RP. The effects of samariumcobalt magnets and pulsed electromagnetic fields on tooth movement. Am J Orthod Dentofacial Orthop 1995;107:578-88.

15) Kawasaki K, Shimizu N. Effect of low energy laser irradiation on bone remodeling during experimental tooth movement in rats. Laser Surg Med 2000;26:282-91.

16) Leiker BJ, Nanda RS, Currier GF, Howes RL, Sinha PK. The effects of exogenous prostaglandins on orthodontic tooth movement in rats. Am J Orthod Dentofacial Orthop 1995;108:380-8.

17) Bassett C. Pulsing electromagnetic fields: A new approach to surgical problems. In: Buchwald H, Vargo R, editors. Metabolic surgery. New York: Grune and Stratton;1978.p.255-306. 
Egyptian

Orthodontic Journal

18) Liou EJ, Huang CS. Rapid canine retraction through distraction of the periodontal ligament. Am J Orthod Dentofacial Orthop 1998; 114:372-82.

19) Ren A, Lv T, Kang N, Zhao B, Chen Y, Bai D. Rapid orthodontic tooth movement aided by alveolar surgery in beagles. Am J Orthod Dentofacial Orthop 2007;131:160.el-10.

20) Brugnami F, Caiazzo A, Dibart S. Lingual orthodontics: Accelerated realignment of the "social six" with piezocision. Comped Contin Educ 2013;34:2-4.

21) Dibart S, Sebaoun JD, Surmenian J. Piezocision: A minimally invasive, periodontally accelerated orthodontic tooth movement procedure. Compend Contin Educ 2009;30:342-4.

22) Keser E, Dibart S. Sequential piezocision: A novel approach to accelerated orthodontic treatment. Am J Orthod Dentofacial Orthop 2013;144:879-89.

23) Vecellotti T, Podesta A. Orthodontic microsurgery: a new surgically guided technique for dental movement. Int $\mathrm{J}$ Periodontics Restorative Dent 2007;27:325-31.

24) Kotrikova B, Wirtz R, Krempien R, Blank J, Eggers G, Samiotis A. Piezosurgery-a new technique in cranial osteology. Int Oral Maxillofac surg 2006;35:461-5.

25) Roblony M, Polini F, Costa F, Vercellotti T, Politi M. Piezoelectric bone cutting in multipiece maxillary osteotomies. J Oral Maxillofac Surg 2004;62:759-61.

26) Kim SJ, Park YG, Kang SG. Effects of corticision on paradental remodeling in orthodontic tooth movement. Angle Orthod 2009; 79"284-91.

27) Almohaimeed M. Piezosurgery in surgically assisted orthodontic treatment. Life Sci J 2014;11(1):141-144.

28) Abbas N, Sabet N, Hassan I. Evaluation of corticotomy-facilitated orthodontics and piezocision in rapid canine retraction. Am J Orthod Dentofacial Orthop 2016;149:473-80. 
Egyptian

Orthodontic Journal

29) Mittal S.K, Sharma R, Singla A. Piezocision assisted orthodontics: a new approach to accelerated orthodontic tooth movement. J Innovative Dentistry 2011;1.

30) Dibart S, Surmenian J.D, Montesani L. Rapid treatment of Class II malocclusion with piezocision: two case reports. Int J Periodontics Restorative Dent 2010;30(5):487-493.

31) Vercellotti T, Nevins M.L, Kim D.M et al. Osseous response following respective therapy with piezosurgery. Int J Periodontics Restorative Dent 2005;25(6):543-549.

32) Nimeri G, Kau C, Aboukheir N, Corona R. Acceleration of tooth movement during orthodontic treatment-a frontier in orthodontics. Progress in Orthodontics 2013,14:42.

33) Hassan NHANE, SA IT. The effectof using piezocision technique in orthodontic tooth movement on the periodontal condition. Egypt Dent J.2011;57:30-47.

34) Keser EI, Dibart S. Piezocision-assisted invisalign treatment. Compend Contin Educ Dent. 2011;32(2):46-8. 50-41. 